\title{
Convivências junto à cruz (Jo 19,25-27)
}

\section{Coexistences nearby the cross (Jn 19:25-27)}

\author{
Matthias Grenzer
}

\section{Resumo}

A micronarrativa em Jo 19,25-27 contempla, de modo especial, a questão das convivências entre as pessoas. No caso, as quatro mulheres junto à cruz - a mãe de Jesus, a irmã dela, Maria de Clopas e Maria Madalena representam convivências pregressas, baseadas em parentesco, vizinhança e gênero. O Crucificado, por sua vez, insiste em um novo tipo de convivência, sem, necessariamente, anular as convivências antigas, sendo que as novas relações devem encontrar seu fundamento na acolhida amorosa do outro, principalmente daquele que é injustiçado e, por isso, tem sua sobrevivência digna ameaçada. $\mathrm{O}$ artigo aqui apresentado propõe um estudo exegético de Jo 19,25-27, partindo de uma análise linguístico-literária da micronarrativa em questão. Valorizando, em seguida, os paralelismos existentes no Evangelho segundo João, o estudo teológico procura descrever os pormenores das convivências favorecidas pelo Crucificado. Como personagens marcantes, a mãe de Jesus e o discípulo amado adquirem nesse contexto um simbolismo extraordinário.

Palavras-chave: Convivência. Cruz. Evangelho segundo João. Maria. Discípulo amado.

\section{Abstract}

The micronarrative in Jn 19:25-27 contemplates, in a special way, the coexistence among people. In regard, the four women nearby the cross - Jesus' mother, her sister, Maria de Clopas, and Maria Magdalena - represent a living 
together which there already was, based on familiarity, neighborhood and gender. On the other hand, the crucified insists on a new kind of coexistence. The new relationship must find out its foundation in a kind welcoming to others, specially, those wronged that because of this have their dignified survival threatened. This new coexistence must not eliminate the ancient familiarity. This article proposes an exegetical study of Jn 19:25-27, starting with a linguistic-literary analysis of the micronarrative. Subsequently, it will be valorized the parallelisms in the Gospel according to John. The theological study will describe the details in regard to the coexistence favored by the crucified. As remarkable characters, Jesus' mother and the beloved disciple acquire an extraordinary symbolism in this context.

Keywords: Coexistence. Cross. Gospel according to John. Mary. Beloved disciple.

\section{Introdução}

Os organizadores do VII Simpósio de Teologia da PUC-Rio convidaram a comunidade acadêmica a "desenvolver uma reflexão bíblico-teológica que responda aos desafios de uma visão atualizada sobre Maria". ${ }^{1}$ De certo, já existem estudos bem fundamentados e abrangentes sobre Maria, tanto bíblicos quanto sistemáticos e pastorais. Alguns deles foram elaborados no Brasil. ${ }^{2}$ Nesse sentido, novas pesquisas bíblico-teológicas sobre a mãe de Jesus hão de

\footnotetext{
${ }^{1}$ VII SIMPÓSIO DE TEOLOGIA PUC-RIO. Maria: Escritura, Teologia e Religiosidade. Ano Jubilar Mariano: 300 anos de História. Disponível em: <http://www.simposiopucrio.teo.br/apresentacao.htm>. Acesso em 24 de fevereiro de 2017. No dia 16 de maio de 2017, a pesquisa aqui publicada foi apresentada no referido Simpósio, sendo que, junto ao Prof. Dr. Rudolf Eduard Von Sinner (EST - RS), pude compor a Mesa dedicada à temática "Maria e Ecumenismo".

${ }^{2}$ MURAD, A. Maria, toda de Deus e tão humana: compêndio de Mariologia. São Paulo: Paulinas; Aparecida: Santuário, 2012; BOFF, C. Introdução à Mariologia. Petrópolis: Vozes, '2012; IWASHITA, P. K. "Maria na Teologia Simbólica da Patrística". Revista de Cultura Teológica 87 (2016), pp. 178-201; IWASHITA, P. K. "O culto mariano e o arquétipo do feminino: elementos antropológicos e psicológicos". Atualidade Teológica 51 (2015), pp. 546-566; IWASHITA, P. K. “A presença de Maria na nova evangelização". Atualidade Teológica 46 (2014), pp. 104-126; IWASHITA, P. K. "Maria no Vaticano II: renovação na Mariologia". Atualidade Teológica 48 (2014), pp. 554-571; BRUSTOLIN, L. A. Eis tua mãe: síntese de Mariologia. São Paulo: Paulinas, 2017; SCHERER, C. O. P. Viva a mãe de Deus e nossa! Carta pastoral à Arquidiocese de São Paulo por ocasião do Ano Mariano Nacional 2016 -2017. São Paulo: Vicariato para a Pastoral da Comunicação, 2016.
} 
se inserir numa história de investigações que, no caso da teologia cristã latinoamericana, adquiriu traços e características próprios nos últimos cinquenta anos. $^{3}$

Isso, por sua vez, não isenta quem trabalha agora com pesquisas teológicas de acolher e rever o patrimônio da fé cristã. No caso, o tricentenário do encontro da imagem de Nossa Senhora da Conceição nas águas do Rio Paraíba (1717-2017) se torna um belo estímulo para ir, outra vez, ao encontro daquela personagem que os brasileiros carinhosamente chamam de Nossa Senhora. Existe, como afirmado anteriormente, a necessidade de uma visão atualizada, renovada e, por excelência, cada vez mais aprofundada sobre Maria. Mais ainda, a teologia precisa prestar um serviço público ao povo brasileiro. Seja lembrado, nesse sentido, que - em 16 de julho de 1930, através de um decreto do papa Pio XI - Nossa Senhora da Conceição Aparecida foi proclamada Padroeira do Brasil. Além disso, a Catedral Basílica de Nossa Senhora Aparecida - consagrada, em 04 de julho de 1980, pelo papa João Paulo II - é chamada de Santuário Nacional e - através da Lei 6.802, publicada em 30 de junho de 1980 - a Presidência da República declarou o dia 12 de outubro feriado nacional, consagrando-o a Nossa Senhora, Padroeira do Brasil. De certa forma, é curioso um Estado laico insistir na consagração do povo a Maria.

No entanto, sem uma visão atualizada da mãe de Jesus, esses espaços geográficos e/ou cronológicos, por mais que, em determinado momento, tenham sido consagrados, correm o risco de esvaziar-se de seu sentido. Cabe, portanto, à teologia, ciência que estuda criticamente a fé cristã, a tarefa de apresentar estudos que indiquem a importância e representatividade de Maria. E isso não somente em vista de quem pertence a determinada Igreja, mas em relação a todas as pessoas, cristãs e não cristãs, especialmente quando se relacionam em busca de sua sobrevivência, envolvendo estruturas familiares, comunitárias e sociais. Assim, a questão se torna também ecumênica,

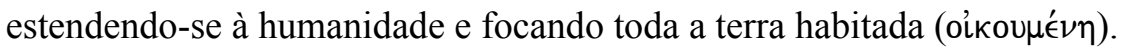

Contudo, qualquer reflexão teológica que visa a um conhecimento da fé cristã e, no caso, a um personagem pertencente a essa tradição religiosa envolve releituras e análises exegéticas das tradições neotestamentárias. Assim, em vista das perguntas esboçadas acima, a pesquisa aqui apresentada se propõe

\footnotetext{
${ }^{3}$ MANZATTO, A.; GRENZER, M. "Teologia cristã latino-americana: anotações sobre a Área de Concentração do Programa de Estudos Pós-Graduados em Teologia da PUC-SP”. Revista de Cultura Teológica 89 (2017) (no prelo).
} 
a realizar um estudo do que é narrado no Evangelho segundo João, capítulo 19 , versículos 25 a 27 . A cena, formada por três versículos apenas, aproxima o ouvinte-leitor do quarto Evangelho "à cruz de Jesus" (v. 25), transmitindolhe as últimas palavras dirigidas por Jesus à "sua mãe" e ao "discípulo que ele amava" (vv. 26-27). Embora curto, o trecho é capaz de destacar o modelo de fé e comportamento que pertence à tradição religiosa do cristianismo.

Desde então, passaram-se praticamente vinte séculos, sendo que hoje se vive numa sociedade multicultural e plurirreligiosa. Isso, porém, valia também para o ambiente debaixo da cruz de Jesus, no ano 30 em Jerusalém. Naquele momento, era tão necessário refazer as relações quanto hoje, envolvendo, no caso, uma mãe que teve o filho brutalmente assassinado, detalhe que, talvez, ganhe maior atualidade. Enfim, seja permitida agora a releitura de Jo 19,2527, para, no decorrer do estudo, descobrir ou não se o que é pensado nesta pequena narrativa continua sendo uma boa-nova capaz de oferecer orientação ao ouvinte-leitor na busca de convivências mais pacíficas e justas, visando à salvação da humanidade.

\section{O texto e sua organização literária}

Para favorecer a compreensão de Jo 19,25-27, o texto grego e sua tradução para o português são reescritos de forma sequenciada. No caso do texto grego, os editores da edição crítica de The Greek New Testament não apresentam nenhuma variante aos versículos 25-27, ou seja, os antigos manuscritos gregos e as antigas traduções contêm exatamente o mesmo texto. ${ }^{4}$

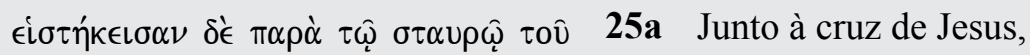

$$
\begin{aligned}
& \text { 'I }
\end{aligned}
$$

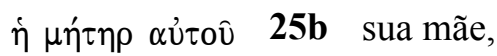

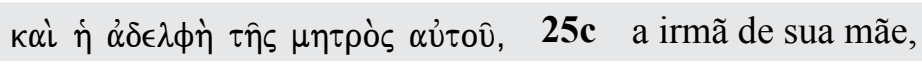

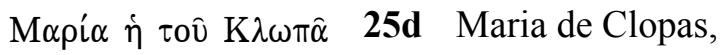

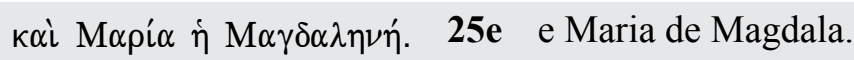

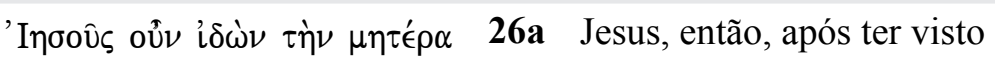

$$
\begin{aligned}
& \text { a mãe }
\end{aligned}
$$

\footnotetext{
${ }^{4}$ INSTITUTE FOR NEW TESTAMENT TEXTUAL RESEARCH. The Greek New Testament. 5 ed. Stuttgart: Deutsche Bibelgesellschaft, 2014.
} 


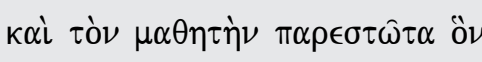

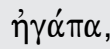
$\lambda \lambda^{\prime} \gamma \in \mathrm{l} \tau \hat{\eta} \mu \eta \tau \rho i ́$,

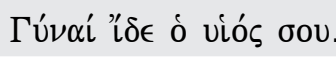
$\epsilon \hat{\imath} \tau \alpha \lambda^{\prime} \epsilon \epsilon \epsilon$ $\tau \hat{\omega} \mu \alpha \theta \eta \tau \hat{n}$,

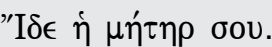

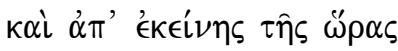

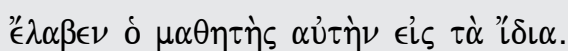

$26 b$ discípulo que amava,

26c disse à mãe:

26d "Mulher, vê teu filho!"

27a Depois disse ao discípulo:

27b "Vê tua mãe!"

27c E, a partir daquela hora,

27d o discípulo a acolheu entre os seus.

No início do versículo 25 ocorre uma mudança de sujeito. Enquanto, nos versículos anteriores, "quatro soldados" foram focados, justamente aqueles que "crucificaram Jesus" (vv. 23-24), agora quatro mulheres ganham a atenção do ouvinte-leitor: "a mãe" de Jesus (v. 25b), "a irmã da mãe" de Jesus (v. 25c), "Maria de Clopas" (v. 25d) e "Maria de Magdala" (v. 25e). A conjunção aqui compreendida como adversativa - ver a palavra "porém" no versículo 25a $(\delta \grave{\prime} \dot{\epsilon})$-, logo na segunda posição da frase, ajuda a sublinhar tal contraste, especialmente quando se observa a partícula afirmativa na frase anterior (v. 24: $\mu^{\prime}{ }^{\prime} \nu$ ). Quer dizer, "de um lado" estavam os "soldados" romanos (v. 24) e "do outro" (v. 25a), o grupo das mulheres. ${ }^{5}$

Além disso, justamente no início, a narrativa insiste num determinado lugar e nas personagens que o ocupam. Com a menção, na posição de objeto indireto, "junto à cruz de Jesus" (v. 25a), o Crucificado ganha destaque antes de o sujeito quádruplo ser citado. Com isso, a narrativa estabelece, antes de tudo, o ponto de referência, realçando sua importância. Além disso, outros elementos na frase ajudam a manter o olhar na "cruz de Jesus". No caso, a preposição grega traduzida aqui como "junto a" (v. 25a: $\pi \alpha \rho \grave{\alpha}$ ) situa as mulheres, sujeito da frase, em relação ao Crucificado. Ou seja, elas estão posicionadas justamente "ao lado", "perto" ou "próximo à cruz de Jesus", sendo que tal proximidade, por causa da posição elevada do Crucificado, se dá debaixo da cruz. Além disso, a dupla presença do pronome pessoal na terceira pessoa do genitivo singular masculino relaciona, de forma marcante, a primeira das quatro mulheres mencionadas

\footnotetext{
${ }^{5}$ BROWN, R. E. A morte do Messias: comentário das narrativas da paixão nos quatro Evangelhos. São Paulo: Paulinas, 2011, v. II, p. 176.
} 
com o Crucificado, dizendo, por duas vezes, que se trata da "mãe dele" ou de "sua mãe" (v. 25b.c).

No mais, também o valor temporal e semântico do verbo, o qual inicia a sequência das palavras que compõem a primeira frase da cena, oferece destaque ao posicionamento das quatro mulheres. A rara forma do mais-queperfeito do verbo, cujo aspecto temporal indica, na língua grega, "um estado pertencente ao passado", é traduzido aqui como "haviam permanecido" (v. 25a: $\epsilon i \sigma \tau \eta ́ \kappa \epsilon \iota \sigma \alpha \nu \delta \epsilon$ ¿ $\sigma \tau \eta \mu \iota) .{ }^{6}$ Subentende-se um "firme manter-se", no sentido de elas "pararem" ou "se colocarem" em tal posição a fim de, determinantemente, "resistirem" naquele lugar, mesmo em meio aos acontecimentos terríveis.

$\mathrm{Na}$ segunda frase da pequena cena, o movimento se inverte. Agora é "Jesus" (v. 26a) que, ocupando a posição de sujeito, se aproxima de quem está perto dele. Seu olhar se dirige à "mãe" (v. 26a) e ao "discípulo que amava" (v. 26b). No caso, são especialmente chamativos os diversos paralelismos trabalhados na cena. Observa-se que Jesus, "após ter visto" os seus (ver o particípio aoristo íćv no versículo 26a), pede à "sua mãe" e ao "discípulo amado" que também eles "vejam" (v. 26d.27b). Ou seja, com o emprego do imperativo aoristo singular "vê" ('ڤં $\epsilon)$ da mesma raiz verbal, os três personagens envolvidos na cena se encontram interligados numa só dinâmica.

Outro paralelismo ajuda a introduzir e posicionar "o discípulo que Jesus amava" (v. 26b). Se de um lado as mulheres "haviam permanecido junto à

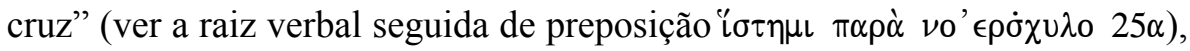
do outro o discípulo também é caracterizado como "quem permaneceu junto" (ver o particípio perfeito $\pi \alpha \rho \epsilon \sigma \tau \hat{\omega} \tau \alpha$ da raiz verbal $\pi \alpha \rho i ́ \sigma \tau \eta \mu \iota$ no versículo 26b). Ou seja, destaca-se duplamente a mesma atitude.

Voltando a atenção a Jesus, este "vê" (v. 26a), "ama" (v. 26b) e "diz" (v. 26c.27a). Trata-se de palavras decisivas aos que "permaneceram junto" (v. 25a.26b) a ele. Diante da morte, ocorre uma sequência marcante de ações.

Junto a Jesus, Maria ganha maior atenção. Sem que se mencione o nome dela, algo característico a todo o Evangelho segundo João, ela aparece, na pequena cena, cinco vezes como "mãe" (v. 25b.c.26a.c.27b) e uma vez

\footnotetext{
${ }^{6}$ BLASS, F.; DEBRUNNER, A. (revisado por REHKOPF, F.). Grammatik des neutestamentlichen Griechisch. Göttingen: Vandenhoeck \& Ruprecht, ${ }^{17} 1990$, p. 282. Na língua portuguesa, $\mathrm{o}$ aspecto temporal do mais-que-perfeito remete, diferentemente, a um passado anterior àquele apresentado pelo pretérito perfeito.
} 
como "mulher" (v. 26d). ${ }^{7}$ Também o pronome pessoal no acusativo singular

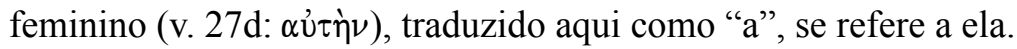

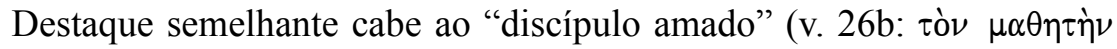

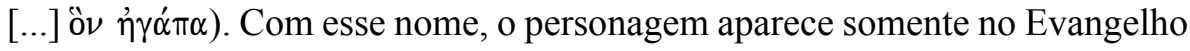
segundo João, sendo que ganha presença nas cenas da ceia de despedida (Jo 13,23), da morte de Jesus (Jo 19,26) e da aparição do Ressuscitado (Jo 21,7.20). ${ }^{8}$ Outra vez, como testemunha do sepulcro vazio que "vê e crê" (Jo 20,9), ele é chamado de "discípulo de que Jesus gostava" (Jo 20,2:

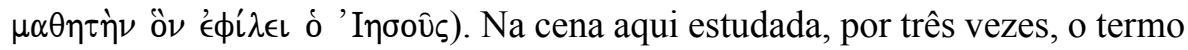
"discípulo" o descreve (v. 26b.27a.d). Além disso, ele se torna "filho" (v. 26d). Mais ainda, o "discípulo amado" se torna sujeito atuante na frase final, sendo que "acolhe a mãe de Jesus entre os seus" (v. 27d).

Ambas as personagens, a "mãe de Jesus" e o "discípulo amado", estão conectadas entre si por se tornarem destinatárias dos dois únicos discursos diretos de Jesus. Ouvem-se ou leem-se duas ordens bem paralelas: "Mulher, vê teu filho!" (v. 26d) e "Vê tua mãe!" (v. 27b). Ou seja, além da repetição da forma verbal "vê" (v. 26d.27b: "น $\delta \epsilon$ ) e do pronome pessoal da segunda pessoa do genitivo singular - ver os dois termos aqui traduzidos como "teu" e "tua" que, em grego, apresentam a mesma forma (v. 26d.27b: oou) -, outro paralelismo une as duas falas - ver as duas expressões que trazem a ideia de um parentesco: "filho" (v. 26c) e "mãe" (v. 27b).

No final, a micronarrativa aqui estudada traz, de forma marcante, uma notícia cronológica. Descreve-se que, com a morte de Jesus e a tarefa de refazer as relações junto à cruz - ou seja, justamente "a partir daquela hora"

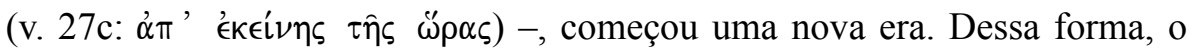
lugar da "cruz de Jesus" (v. 25a), mencionado no início da cena, e o tempo ("a partir daquela hora"; v. 27c), lembrado no final da cena, funcionam como marcadores que molduram e delimitam a pequena unidade literária em Jo 19,25-27.

\footnotetext{
${ }^{7}$ Veja o nome de "Maria", "esposa de José" e "mãe” de Jesus, em Mt 1,16.18.20; 2,11; 13,55; Mc 6,3; Lc 1,27.30.34.38.39.41.46.56; 2,5.16.19.34; At 1,14.

${ }^{8}$ Para Johannes BEUTLER, João Batista, de forma marcante, acompanha Jesus na primeira parte do quarto Evangelho (Jo 1-10), Lázaro, na segunda parte (Jo 11-12), e o "discípulo amado" na última parte (Jo 13-21) (Das Johannesevangelium: Kommentar. Freiburg: Herder, 2013, p. 327.386). Seja mencionado que o Evangelho segundo João se compreende como "testemunho desse discípulo" (Jo 21,24).
} 


\section{Estudo teológico}

Após a breve familiarização com a configuração linguístico-literária do texto em Jo 19,25-27, originalmente composto em grego, o estudo aqui apresentado se dirige à investigação da reflexão teológica promovida pela micronarrativa. De acordo com a temática estudada no VII Simpósio de Teologia da PUC-Rio, seja especialmente acolhido o "desafio de uma visão atualizada sobre Maria", com a intenção de destacar os aspectos que o Evangelho segundo João, na narrativa aqui estudada, atribui à mãe de Jesus. ${ }^{9}$ Quais são as características que Maria assume "junto à cruz de Jesus" (v. 25a)? Em que sentido ela se torna modelo de fé e comportamento para os ouvintes-leitores do quarto Evangelho, sobretudo em vista da árdua tarefa de, nos momentos mais delicados, reconstruir as convivências?

\subsection{Convivências já existentes}

A micronarrativa aqui estudada apresenta, inicialmente, um grupo formado por quatro mulheres..$^{10}$ Narra-se, pois, que, "junto à cruz de Jesus, haviam permanecido a mãe dele, a irmã de sua mãe, Maria de Clopas e Maria Madalena" (v. 25). A escassez de informações torna a compreensão da cena mais exigente. Contudo, ao valorizar o que realmente é narrado, surge uma primeira impressão no que se refere à questão das convivências entre as personagens participantes da cena.

A “mãe de Jesus" (v. 25b) encabeça a lista formada por quatro mulheres. Porventura esse detalhe quer indicar que lhe cabe algum tipo de liderança? De forma direta, o texto não o diz. Em vez disso, afirma-se expressamente que ela é a "mãe de Jesus", o "crucificado" (v. 25a-b). Quer dizer, é o parentesco que ganha destaque. Trata-se da mãe de um filho que está sendo assassinado, por sofrer a pena capital após um julgamento sumário, cheio de contradições e motivações político-religiosas. Nesse sentido, o sofrimento humano atinge, de forma incomparável, justamente a mulher que gestou tal vida debaixo de seu coração. Assim, parece ser óbvio que a mãe, com suas dores, é mencionada em primeiro lugar.

\footnotetext{
${ }^{9}$ VII SIMPÓSIO DE TEOLOGIA PUC-RIO. Maria: Escritura, Teologia e Religiosidade. Ano Jubilar Mariano: 300 anos de História (ver nota 1).

${ }^{10}$ Sobre "o papel de relevo da mulher" no Evangelho segundo João, ver ARAÚJO, Gilvan Leite de. "Jesus e a Samaritana". Revista de Cultura Teológica 87 (2016), p. 233.
} 
Contudo, a "mãe" de Jesus (v. 25a-b) é acompanhada por outras mulheres. O Evangelho segundo João destaca, na segunda posição de sua lista, a tia de Jesus, ou seja, "a irmã da mãe dele" (v. 25c). Outra vez, a narrativa não menciona o nome da pessoa em questão. Como a "mãe" do Crucificado (v. 25b.c), também a tia fica no anonimato. No entanto, o termo "irmã" (v. 25c) realça, novamente, o parentesco. Surge a imagem de mulheres da mesma família, no caso irmãs, unidas num momento extremamente delicado marcado pela dor. Aliás, esse tipo de solidariedade feminina parece corresponder, para além de qualquer contraste cultural, a uma experiência que a humanidade tem em comum. Seja lembrado como o Evangelho segundo Lucas narra que Maria, mãe de Jesus, foi visitar sua "parenta Isabel", grávida no "sexto mês", "para, cerca de três meses, permanecer com ela" (Lc 1,36.56). Enfim, a única menção da tia de Jesus em todo o Novo Testamento ocorre no trecho aqui estudado. Junto à sua "irmã", a qual, como "mãe", acompanha seu filho Jesus ao morrer na "cruz" (v. 25a-c), ela convive com a dor no ambiente familiar.

A terceira mulher "junto à cruz de Jesus" (v. 25a) é "Maria de Clopas" (v. 25d). Novamente, a narrativa transmite a ideia de parentesco. No caso, essa Maria é conhecida como filha, mulher, irmã ou mãe de Clopas. Talvez a primeira possibilidade seja a mais provável. ${ }^{11}$ Contudo, não há como defini-lo, uma vez que o personagem de Clopas (v. $25 \mathrm{~d}$ : K $\lambda \omega \pi \hat{\alpha} \varsigma$ ) somente aparece aqui. ${ }^{12}$ Também não é possível saber se "Maria de Clopas" (v. 25d) é parenta de "Jesus" (v. 25a), da "mãe dele" (v. 25b) e/ou da "irmã da mãe dele" (v. 25c). Contudo, também ela é apresentada como quem pertence a uma família, justamente àquela que tem Clopas como ponto de referência. Com isso, ela certamente compreende a dor do Crucificado e dos familiares dele, sendo que todos eles estão "a seu lado" (v. 25a). Enfim, a proximidade de Maria de Clopas às duas irmãs, parentes de Jesus, pode ser o resultado de uma solidariedade tanto familiar como interfamiliar, sendo que uma família indefesa é brutalmente atingida pela violência de um regime opressivo, instalado pelo império romano, e por ódios e cumplicidades criminosas de lideranças pertencentes ao povo judeu.

A quarta e última mulher mencionada na pequena lista formada pelas quatro mulheres é "Maria Madalena", ou seja, "Maria de Magdala" (v. 25e). Ela

\footnotetext{
${ }^{11}$ Ver a discussão em BROWN, R. E. A morte do Messias: comentário das narrativas da paixão nos quatro Evangelhos. São Paulo: Paulinas, 2011, v. II, pp. 176-177 (nota 81).

${ }^{12}$ Com nome semelhante, mas levemente diferente, conhece-se "Cléofas" (K $\left.\lambda \epsilon \omega \pi \hat{\alpha} \varsigma\right)$, um dos discípulos de Emaús (Lc 24,18).
} 
tem uma presença bastante ampla nos quatro Evangelhos. Trata-se de uma das "mulheres" que, "curadas" por Jesus (Mc 16,9; Lc 8,2), o "seguiram" "desde a Galileia" (Mc 15,41; Lc 8,2). Mais ainda, Maria Madalena é testemunha da morte - seja de perto (Jo 19,25), seja "de longe" (Mc 15,40; Mt 27,55-56; Lc 23,49) -, do sepultamento (Mc 15,47; Mt 27,61; Lc 23,55) e da ressurreição de Jesus, visto que justamente ela "testemunha" e anuncia o Ressuscitado aos discípulos (Mc 16,1.9; Mt 28,1; Lc 24,10; Jo 24,1.11.16.18). ${ }^{13}$

No entanto, a micronarrativa aqui estudada de forma alguma transmite a ideia de um parentesco entre Maria Madalena e a família de Jesus. Destacase, por sua vez, a origem geográfica dela. "Maria" é de "Magdala" (v. 25e). Como as "notícias geográficas" adquirem, no Evangelho segundo João, em parte uma "função simbólica", indicando, como "linques intertextuais", "potenciais semânticos adicionais", o vilarejo de "Magdala" (v. 25e) lembra ao ouvinte-leitor a Galileia e Cafarnaum. ${ }^{14}$ Justamente após o primeiro sinal em "Caná da Galileia" (Jo 2,1-12), Jesus "tinha descido a Cafarnaum, ele, sua mãe, seus irmãos e seus discípulos" (Jo 12,12). Em outro momento, ao estar novamente em "Caná", "curou”, à distância, "o filho de certo funcionário real que estava doente em Cafarnaum" (Jo 4,46-54). Também o sinal de Jesus caminhar sobre o mar (Jo 6,16-21) ocorreu quando os discípulos estavam atravessando o lago da Galileia "rumo a Cafarnaum" (Jo 6,17). E foi em "Cafarnaum" que "a multidão buscou Jesus" após o sinal da multiplicação dos pães (Jo 6,24), sendo que Jesus lhe profere o discurso sobre o pão da vida na "sinagoga de Cafarnaum" (Jo 6,59). Enfim, Jesus pertence à "Galileia" (Jo 1,43 ), pois repetidamente "se dirige à Galileia", "percorrendo" essa região e "permanecendo" ali (Jo 4,3.43.45.46-47.54; 7,1.9). Ou seja, por mais que ele mesmo "testemunhe que um profeta não é honrado em sua própria pátria" (Jo 4,44) e que "outros" duvidem da "vinda do Cristo" ou de um "profeta da Galileia" (Jo 7,41.52), Jesus pertence a tal região, onde, a uma distância pequena de uma hora a pé de Cafarnaum, se encontra também "Magdala" (v. 25e). Portanto, Maria Madalena, além de seguidora, é conterrânea do galileu "Jesus de Nazaré" e da família dele (Jo 1,45-46).

Resumindo: na cena aqui estudada, o Evangelho segundo João transmite a ideia de que, em relação às quatro mulheres "junto à cruz de Jesus" (v. 25a),

\footnotetext{
${ }^{13}$ Ver o excurso sobre "Quem foi Maria de Magdala" em: BÖSEN, W. Ressuscitado segundo as Escrituras: fundamentos bíblicos da fé pascal. São Paulo: Paulinas, 2015, pp. 136-144.

${ }^{14}$ KÜGLER, J. "Das Johannesevangelium”. In: EBNER, M.; SCHREIBER, S. (Org.). Einleitung in das Neue Testament. Stuttgart: Kohlhammer, 2008, p. 209.
} 
existem convivências baseadas em gênero e parentesco, em solidariedade interfamiliar e vizinhança, no caso, a pertença à mesma região, sendo que a Galileia periférica era tradicionalmente menosprezada por quem pertencia a Jerusalém e/ou à Judeia. Com isso, a "mãe" de Jesus (v. 25b-c) se encontra inserida em determinada comunidade. De certo modo, ela representa Israel e o povo judeu, e isso justamente no momento de ela sofrer, indescritivelmente, com as injustiças apoiadas pelas lideranças de seu próprio povo. Mas há quem lhe faça companhia: sua "irmã" (v. 25c), "Maria de Clopas" (v. 25d) e "Maria de Magdala" (v. 25e).

Historicamente, é impossível verificar a verossimilidade da presença de familiares e seguidores junto à cruz, algo somente narrado pelo Evangelho segundo João. ${ }^{15}$ Teologicamente, por sua vez, "a proximidade à cruz de Jesus" (v. 25a) é de fundamental importância, sendo que possibilita a ação do Crucificado na vida de quem não se afasta dele.

\subsection{O agir do Crucificado}

Antes da consumação de sua morte (Jo 19,28-30), Jesus revela sua preocupação com quem lhe pertence. Ao iniciar a descrição da ação do Crucificado, a narrativa joanina apresenta, primeiramente, o olhar dele. Narra que "Jesus viu a mãe" (v. 26a) e "o discípulo que amava" (v. 26b). Por mais que o ouvinte-leitor pudesse imaginar que ele via também as outras três mulheres - ou seja, "a irmã da mãe" (v. 25c), "Maria de Clopas" (v. 25d) e "Maria Madalena" (v. 25e), uma vez que também elas "haviam permanecido junto à cruz" (v. 25a) -, nesse momento, a narrativa estreita o enfoque. Realça o olhar de Jesus tanto para a "mãe" (v. 26a.c.27b), "mulher" (v. 26d) que sofre com a morte injusta do filho, como para o "discípulo amado" (v. 26b), contemplado como "filho" (v. 27a). Quer dizer, ante sua morte, Jesus se emociona com a dramaticidade da vida, semelhantemente ao momento em que "chorou" ao "ver" Maria, irmã de Lázaro, "morto havia quatro dias" (Jo 11,34-35.39).

O motivo de Jesus ver alguém ou ser visto por alguém é trabalhado amplamente na macronarrativa do Evangelho segundo João. No caso, Jesus "viu" Natanael (Jo 1,47-48) e lhe anunciou que "veria coisas maiores" (Jo 1,50). Em Jerusalém, na "piscina junto à Porta das Ovelhas" (Jo 5,2), Jesus "viu um homem doente havia trinta e oito anos" (Jo 5,5-6). Também em

\footnotetext{
${ }^{15}$ Ver a abordagem em BROWN, R. E. A morte do Messias: comentário das narrativas da paixão nos quatro Evangelhos. São Paulo: Paulinas, 2011, v. II, pp. 190-193; 401-403.
} 
Jerusalém, ele "viu um homem que era cego desde o nascimento" (Jo 9,1). Ambos foram curados por Jesus. Além disso, Jesus "viu Maria", irmã de Lázaro, "e os judeus que se lamentavam" por causa da morte deste último, e "se comoveu" (Jo 11,33). Ou seja, ao ver pessoas necessitadas, seja em termos morais, seja em físicos, seja em emocionais, Jesus age.

Em correspondência a essa circunstância, o Evangelho segundo João convida seus ouvintes-leitores a também verem Jesus. Diversas personagens se tornam modelos de comportamento nesse sentido. Há os "dois discípulos" de João Batista que foram "ver onde Jesus morava" e "permaneceram com ele" (Jo 1,39). Também Natanael foi convidado por Filipe a "ver" Jesus (Jo 1,46) e Nicodemos devia "nascer de novo" para "ver o Reino de Deus" (Jo 3,3; 7,52). A Samaritana, após seu encontro com Jesus, convidou seu povo a "ver o homem" que talvez fosse o "Cristo" (Jo 4,29). Maria, irmã de Lázaro, por sua vez, é caracterizada como aquela que, ao "ver Jesus, caiu aos pés dele" (Jo 11,32).

Enfim, ser visto por Jesus e/ou vê-lo implica uma decisão. No caso, a pessoa, ao "ver os sinais" realizados por Jesus, pode "crer" nele como enviado pelo Pai (Jo 4,48; 6,14.26.30), semelhantemente a Abraão, que "viu o dia" de Jesus e "se alegrou" (Jo 8,56), ou Isaías, que "viu a glória" de Jesus (Jo 12,41). Em especial, isso vale para Jesus como Ressuscitado. Ao "vê-lo, os discípulos se alegraram" (Jo 20,20.25) e "creram" (Jo 20,27.29). No entanto, também é possível "crer" no Ressuscitado sem "vê-lo" (Jo 20,29). Justamente o "discípulo do qual Jesus gostava" (Jo 21,2) se torna modelo nesse sentido. Narra-se, pois, que ele "entrou no sepulcro" vazio, "viu e acreditou" (Jo 20,8). Não obstante, existe a possibilidade de os homens, "embora tenham olhos, não verem com seus olhos" (Jo 12,40; Is 6,9-10). Assim, "os sumos sacerdotes e guardas viram" Jesus, mas “começaram a gritar: 'Crucifica-o!'” (Jo 19,6). E os "soldados" romanos somente "viram que Jesus já estava morto" (Jo 19,33).

Resumindo: o Evangelho segundo João sublinha a importância de o homem, assim como os gregos, "querer ver Jesus" (Jo 12,21). Ao mesmo tempo sabe que o homem, como Natanael, "anteriormente já é visto" por Jesus (Jo 1,48). Mais ainda, junto a Jesus, o homem deve ver o mais necessitado. Justamente essa dinâmica ocorre na cena aqui estudada. Basta observar o paralelismo referente ao verbo: "Jesus, pois, vê a mãe" (v. 26a) e lhe pede que "veja" seu novo "filho" (v. 26d); "Jesus vê o discípulo que ama" (v. 26a-b) e lhe pede que "veja" sua nova "mãe" (v. 27b). Surge o ideal de Jesus e os seus estarem unidos numa mesma visão, sendo que se enxerga e, por consequência, se acolhe a pessoa sofrida, que está tão próxima. 
O modelo para tal amor leal e solidário é o próprio Crucificado. E, de forma exemplar, o "discípulo amado" (v. 26b) é testemunha disso. Por "haver permanecido junto à cruz" (v. 25a.26b), presenciou, junto às quatro mulheres, a morte de Jesus e como este "amou os seus até o fim" (Jo 13,1). Assim também se tornou testemunha do Ressuscitado (Jo 20,2.8; 21,7). Ou seja, aquele que "se reclinou sobre o peito de Jesus" (Jo 13,23) descobriu este último como "quem está sobre o peito do Pai" (Jo 1,18). Contudo, para o Evangelho segundo João, que apresenta o "discípulo amado" como seu autor (Jo 21,24) e, na qualidade de "seguidor de Pedro" (Jo 21,20), como representante da comunidade cristã, trata-se de uma relação não exclusiva mas sim paradigmática ou exemplar. Afinal, narra-se também como Jesus "amava Marta, a irmã dela e Lázaro" (Jo 11,5). Mais ainda, ele "amava os seus", ou seja, todos os discípulos "neste mundo" (Jo 13,1.34; 15,9.12), "dando, por amor, sua vida para os amigos" (Jo 15,13).

Enfim, aquele que é "amado pelo Pai" (Jo 3,35; 10,17; 15,9-10; 17,2324.26) e "ama o Pai" (Jo 14,31), justamente por "dar sua vida" (Jo 10,17) e assim "fazer como o Pai ordena" (Jo 14,31), insiste, junto a seus discípulos, numa postura marcada pelo "amor aos outros" (Jo 13,34-35; 15,12.17). E é justamente dessa forma que Jesus quer ser "amado" (Jo 14,15.21.23-24; 15,9-10), pois então será possível que o discípulo experimente o "amor" e a presença de Deus Pai (Jo 14,21.23; 17,23.26) e do próprio Jesus (Jo 14,21.23; $17,26)$. No entanto, também é preciso dizer que, por mais que "Deus ame o mundo" (Jo 3,16), é possível que "os homens amem mais as trevas do que a luz" (Jo 3,19) ou que "amem mais a glória dos homens do que a glória de Deus" (Jo 12,43), em vez de "amarem", por excelência, o próprio Jesus (Jo 21,15-16). Consequentemente, "o amor de Deus", quem sabe, "não está" nas pessoas (Jo 5,42), sendo que, na ausência de "Deus" como "Pai", também não há como "amar" Jesus (Jo 8,42).

Ou seja, a dinâmica do amor, a qual, de forma tão marcante, caracteriza o ensino e a prática de Jesus, ganha sua última concretude "junto à cruz" (v. 25a). O Evangelho segundo João continua a apresentar Jesus como quem "ama" (v. 26b). Assim, ele ainda "vê sua mãe e seu discípulo" (v. 26a-b), sendo que tal olhar amoroso se transforma em "dizeres" (v. 26c.27a). Tais palavras, por sua vez, formando os únicos dois discursos diretos na micronarrativa estudada aqui (v. 26d.27b), prescrevem outra vez que, a partir dessa "hora" (v. 27c) da morte do Crucificado, a "visão" de Jesus (v. 26a) deve se tornar a "visão" dos seus (v. 26d.27b). Como isso pode correr, é narrado no final da cena. 


\subsection{Novas convivências}

Seguindo os elementos da narrativa aqui estudada, percebe-se que o "discípulo amado" (v. 26b) age de acordo com o que Jesus lhe "disse" (v. 27a), cumprindo a ordem do Crucificado (v. 27b) e, dessa forma, também a ordem anteriormente dada pela "mãe" de Jesus: "Fazei tudo o que ele vos disser" (Jo 2,5). Narra-se, pois, que "o discípulo, a partir daquela hora, acolheu" a mãe de Jesus "entre os seus" (v. 27c-d).

Nasce, assim, um novo tipo de convivência. Uma "mãe" (v. 25b.c.26a.c) e "mulher" (v. 26d), injustiçada pela morte violenta de seu filho, é "acolhida" ou "recebida" justamente por um "discípulo" (v. 26b.27a.d) desse filho assassinado. E tudo isso ocorre como resposta positiva à ordem deixada por esse filho, que insistiu na convivência dos sobreviventes como "filho" (v. 26d) e "mãe" (v. 27b). Aliás, seja lembrado que, para o direito do antigo Israel, "a mãe que perde seu último filho não tem mais rede social" e "necessita de uma pessoa que a adote, normalmente algum outro parente". ${ }^{16}$

Os paralelismos no Evangelho segundo João propõem ainda uma reflexão teológica mais ampla. Ao "acolher" a mãe de Jesus, ou seja, aquela que Jesus the "enviou", o discípulo amado "acolhe" o próprio Jesus e "aquele que o enviou" (Jo 13,20; 5,43-44). Mais ainda, por "acolher o testemunho" e "as palavras" de Jesus (Jo 3,11.32-33; 12,48; 17,8) - e, com isso, "o espírito da verdade que o mundo não acolhe" (Jo 14,17) -, o discípulo ganha "a autoridade de tornar-se filho de Deus" (Jo 1,12). É justamente este o caminho para "acolher, da plenitude dele, graça sobre graça" (Jo 1,16), inclusive o "Espírito Santo" (Jo 20,22).

Não faltam exemplos no Evangelho segundo João que ilustram uma postura contrária àquela que opta pela acolhida amorosa do outro. No caso, Judas "acolheu a coorte" - normalmente cerca de seiscentos soldados - "e os guardas dos sumos sacerdotes e fariseus", a fim de ir ao encontro de Jesus e entregá-lo a seus perseguidores (Jo 18,3). Pilatos, por sua vez, quis que os acusadores judeus "acolhessem" Jesus, "o julgassem segundo a lei deles" e/ ou "o crucificassem" (Jo 18,31; 19,6). Na prática, porém, foi ele quem "o acolheu", justamente para "ordenar que fosse flagelado" e crucificado (Jo 19,1). E "os soldados" romanos são caracterizados como aqueles que "acolheram as vestes" do Crucificado (Jo 19,23). Contrariamente a todos esses, no entanto,

\footnotetext{
${ }^{16}$ BEUTLER, J. Das Johannesevangelium: Kommentar. Freiburg: Herder, 2013, p. 441.
} 
Nicodemos e José de Arimateia, de forma positiva, "acolheram o corpo de Jesus", a fim de sepultá-lo dignamente (Jo 19,40).

Contudo, na micronarrativa aqui estudada, o "discípulo amado" (v. 26b.27a.d), fiel ao mandamento do Crucificado, é descrito como quem se preocupa com "os seus" (v. 27d), sendo que ele "acolhe", de forma exemplar, a mãe de Jesus "entre os seus" ou, literalmente, "entre o que é seu" (v. 27d). Torna-se, assim, semelhante a Jesus, que "amava os seus neste mundo" (Jo 13,1). ${ }^{17}$ Surge, com isso, a convivência indicada por Jesus, algo nada óbvio. Afinal, Jesus mesmo, como "bom pastor" (Jo 10,11), "veio para o que é seu, mas os seus não o acolheram" (Jo 1,11; 10,3-4.12). E, segundo o discurso de despedida de Jesus, o destino dos discípulos não seria diferente. "Se fossem do mundo, o mundo os amaria como algo seu"; seguindo, porém, a proposta diferenciada de Jesus, "o mundo os odiaria" (Jo 15,19).

Resta ainda levar em consideração que, embora as personagens apresentadas na narrativa do quarto Evangelho sejam "reais", "o contexto convida a descobrir um significado mais amplo", no sentido de a mãe de Jesus e o discípulo amado assumirem "um papel típico" e "representativo". ${ }^{18}$ No caso, a mãe de Jesus parece representar Israel, o povo judeu e a família de Jesus. ${ }^{19} \mathrm{O}$ discípulo amado, por sua vez, se caracteriza - em especial, a partir da "segunda referência a ele na crucificação (Jo 19,35)" - como "testemunha ocular e presumivelmente portador da tradição" cristã, representando a comunidade joanina e, com isso, a Igreja. ${ }^{20}$ No entanto, ocorrem interessantes acréscimos. Ao ser confiada a ele, "a mãe de Jesus torna-se a mãe do discípulo e de todos os discípulos", sendo que, com isso, se torna "mãe da Igreja". ${ }^{21}$ Contudo, vale também o seguinte: por ser confiado a ela, o discípulo amado, outra vez, tem visualizadas suas relações com Israel, o povo judeu e a família de Jesus.

\footnotetext{
${ }^{17} \mathrm{Em}$ Jo 13,1, o adjetivo traduzido aqui como "seu(s)" é apresentado no acusativo plural masculino, mas, em Jo $19,27 \mathrm{~d}$, no acusativo plural neutro ( $(\hat{\imath} \delta\llcorner\alpha)$. Ver a mesma forma, precedida pela mesma preposição, em Jo 1,11; 16,32.

${ }^{18}$ MAGGIONI, B. "O Evangelho de João”. In: FABRIS, R; MAGGIONI, B. Os Evangelhos II. 4 ed. São Paulo: Loyola, 2006, p. 471.

${ }^{19}$ Para Juan MATEOS e Juan BARRETO, "a antiga comunidade judaica (a mãe) deve reconhecer como descendência sua a comunidade nova, a dos que romperam com a instituição judaica" (O Evangelho de São João. São Paulo: Paulus, 1999, p. 807).

${ }^{20}$ BROWN, R. E. A morte do Messias: comentário das narrativas da paixão nos quatro Evangelhos. São Paulo: Paulinas, 2011, v. II, p. 183.

${ }^{21}$ MAGGIONI, B. “O Evangelho de João”. In: FABRIS, R.; MAGGIONI, B. Os Evangelhos II. 4 ed. São Paulo: Loyola, 2006, p. 472.
} 


\section{Considerações finais}

A micronarrativa em Jo 19,25-27 traz, de modo especial, uma reflexão sobre convivências já existentes e novas, sendo que estas últimas são pensadas justamente a partir da proximidade ao Crucificado. No final do estudo aqui exposto, seja permitida uma apresentação da reflexão teológica do texto bíblico em questão, a partir de um olhar específico para a personagem da mãe de Jesus.

Seguindo o Evangelho conforme João, Maria sempre é apresentada relacionada a alguém. Nas bodas de Caná, ela está como "mãe", na companhia de Jesus, mas também convive com os "discípulos" de seu filho, os "servidores" daquela casa e toda a comunidade festiva ali presente (Jo 2,111). Depois, novamente como "mãe", ela acompanha Jesus em sua ida para Cafarnaum, sendo que os "irmãos" e "discípulos" de seu filho estão junto (Jo 2,12). Os "judeus" falam dela como "mãe" de Jesus, sendo que afirmam conhecer também o "pai" dele, uma vez que Jesus é tido como "filho de José" (Jo 6,41-42). Junto a seu filho crucificado, Maria é acompanhada por outras três mulheres: "sua irmã", "Maria de Clopas" e "Maria Madalena" (v. 25c-e). Além disso, por "haver permanecido junto", também "o discípulo que Jesus amava" está a seu lado (v. 26b). Enfim, Maria convive com seu povo, com seus familiares, com as mulheres e também com os discípulos de Jesus.

Todavia, justamente essas convivências já existentes ganham nova qualificação a partir da proximidade ao Crucificado. Maria é mais uma vez "vista" por seu filho (v. 26a), sendo que este, em meio a sua paixão e glorificação, lhe "diz" uma última palavra (v. 26c-d). Além disso, ela testemunha como Jesus "diz" outra palavra ao discípulo amado, referindo-se a ela (v. 27a-b). Ambas as palavras insistem na construção de uma nova convivência, a qual, em princípio, já existia de alguma forma. Agora, porém, tal convivência deve ganhar definitivamente as características de uma relação mãe-filho, na qual os dois devem ter a postura de "verem" e "amarem" um ao outro (v. 26d.27b), adotando a "visão" e o "amor" do Crucificado (v. 26a-b).

Pelo que a narrativa joanina informa no final, Maria foi "acolhida" pelo “discípulo" (v. 27d). Ou seja, a partir “daquela hora" (v. 27c), ela passou a fazer parte da nova comunidade, representada pelo discípulo amado. Como mulher, mãe, irmã e judia, Maria aceitou o projeto de construir novas convivências na comunidade daqueles que se propõem a guardar o mandamento do Crucificado. 


\section{Referências bibliográficas}

ARAÚJO, G. L. "Jesus e a Samaritana". Revista de Cultura Teológica 87 (2016), pp. 231-249.

BEUTLER, J. Das Johannesevangelium: Kommentar. Freiburg: Herder, 2013. Tradução brasileira: Evangelho segundo João: comentário. São Paulo: Loyola, 2016.

BLASS, F.; DEBRUNNER, A. (revisado por REHKOPF, F.). Grammatik des neutestamentlichen Griechisch. Göttingen: Vandenhoeck \& Ruprecht, 171990.

BOFF, C. Introdução à Mariologia. Petrópolis: Vozes, ${ }^{6} 2012$.

BÖSEN, W. Ressuscitado segundo as Escrituras: fundamentos bíblicos da fé pascal. São Paulo: Paulinas, 2015.

BROWN, R. E. A morte do Messias: comentário das narrativas da paixão nos quatro Evangelhos. São Paulo: Paulinas, 2011. v. II.

BRUSTOLIN, L. A. Eis a tua mãe: síntese de Mariologia. São Paulo: Paulinas, 2017.

CANTALAMESSA, R. Maria, um espelho para a Igreja. Aparecida: Santuário, 1992.

INSTITUTE FOR NEW TESTAMENT TEXTUAL RESEARCH. The Greek New Testament. Stuttgart: Deutsche Bibelgesellschaft, ${ }^{5} 2014$.

IWASHITA, P. K. "A presença de Maria na nova evangelização". Atualidade Teológica 46 (2014), pp. 104-126.

IWASHITA, P. K. "Maria na Teologia Simbólica da Patrística". Revista de Cultura Teológica 87 (2016), pp. 178-201.

IWASHITA, P. K. "Maria no Vaticano II: renovação na Mariologia". Atualidade Teológica 48 (2014), pp. 554-571.

IWASHITA, P. K. "O culto mariano e o arquétipo do feminino: elementos antropológicos e psicológicos". Atualidade Teológica 51 (2015), pp. 546-566.

KÜGLER, J. "Das Johannesevangelium”. In: EBNER, M.; SCHREIBER, S. (Org.). Einleitung in das Neue Testament. Stuttgart: Kohlhammer, 2008, pp. 208-228. 
MAGGIONI, B. “O Evangelho de João". In: FABRIS, R.; MAGGIONI, B. Os Evangelhos II. São Paulo: Loyola, ${ }^{4} 2006$, pp. 249-497.

MANZATTO, A.; GRENZER, M. "Teologia cristã latino-americana: anotações sobre a Área de Concentração do Programa de Estudos PósGraduados em Teologia da PUC-SP”. Revista de Cultura Teológica 89 (2017). (No prelo).

MATEOS, J.; BARRETO, J. O Evangelho de São João. São Paulo: Paulus, 1999.

MURAD, A. Maria, toda de Deus e tão humana: compêndio de Mariologia. São Paulo: Paulinas; Aparecida: Santuário, 2012.

SCHERER, C. O. P. Viva a mãe de Deus e nossa! Carta pastoral à Arquidiocese de São Paulo por ocasião do Ano Mariano Nacional 2016 -2017. São Paulo: Vicariato para a Pastoral da Comunicação, 2016.

VII SIMPÓSIO DE TEOLOGIA PUC-RIO. Maria: Escritura, Teologia e Religiosidade. Ano Jubilar Mariano: 300 anos de História. Disponível em: <http://www.simposiopucrio.teo.br/apresentacao.htm>. Acesso em 24 de fevereiro de 2017.

Matthias Grenzer Doutor em Teologia pela Faculdade de Filosofia e Teologia St. Georgen em Frankfurt (Alemanha) Professor na Faculdade de Teologia da Pontifícia Universidade Católica de São Paulo São Paulo/SP - Brasil E-mail: mgrenzer@pucsp.br 